Habitar la contingencia. Narrativas juveniles en torno a la COVID-19 en Jalisco, México Igor Israel González Aguirre

Revista Argentina de Estudios de Juventud, dossier temático, e066, 2021

ISSN 1852-4907 | https://doi.org/10.24215/18524907e066

https://perio.unlp.edu.ar/ojs/index.php/revistadejuventud

FPyCS | Universidad Nacional de La Plata

La Plata | Buenos Aires | Argentina

\title{
HABITAR LA CONTINGENCIA
}

\section{NARRATIVAS JUVENILES EN TORNO A LA COVID-19 EN JALISCO, MÉXICO}

\author{
Living through Contingency \\ Youth Narratives about COVID-19 in Jalisco, Mexico
}

Igor Israel González Aguirre

Igor.Gonzalez@academicos.udg.mx

https://orcid.org/0000-0002-8608-0130

Departamento de Estudios sobre los Movimientos Sociales

Centro Universitario de Ciencias Sociales y Humanidades (CUCSH)

Universidad de Guadalajara

México

Palabras clave

juventud

México

COVID-19

narrativas

\section{Resumen}

En este trabajo se exploran las narrativas de jóvenes jaliscienses, de entre 15 y 29 años, que habitan el Área Metropolitana de Guadalajara (ZMG), México,ante la COVID-19. La investigación es de corte cualitativo y se realizó entre marzo de 2020 y marzo de 2021. Entre los hallazgos principales se tienen: la profundización de las desigualdades juveniles; la importancia de lo tecno-digital para la producción de las subjetividades juveniles (a la par de una inesperada tendencia al desapego mediático); y la ineficacia simbólica del discurso institucional-gubernamental en términos del afianzamiento de la seguridad ontológica de la juventud.

\section{Abstract}

Keywords

This paper explores the narratives of young people, between 15 and 29 years old, that inhabit the Guadalajara Metropolitan Area (ZMG), Mexico, in the face of the pandemic youth environment associated with COVID-19. The study is qualitative and was conducted Mexico within March 2020 and June 2021, in Jalisco, Mexico. These are the main findings: the deepening of inequalities experienced by the young population; the importance of the techno-digital realm for the production of youth subjectivities (along with an unexpected tendency to media detachment); and the symbolic ineffectiveness of the institutionalgovernmental discourse for the consolidation of the ontological security of the youth.

Recibido 28/07/2021 Aceptado 12/09/2021 Publicado 27/12/2021 


\section{HABITAR LA CONTINGENCIA \\ NARRATIVAS JUVENILES EN TORNO \\ A LA COVID-19 EN JALISCO, MÉXICO}

Por Igor Israel González Aguirre

\section{Introducción}

Cuando un suceso resulta en extremo sobrecogedor suele dislocar los ejes desde los cuales se interpreta la realidad: coloca tanto a los actores como al entramado institucional ante la necesidad de adecuarse inmediatamente a un entorno contingente. Alain Badiou (2005) y Slavoj Žižek (2014) han denominado a esta situación como acontecimiento. Con el cerco sanitario establecido desde comienzos de 2020 en la ciudad de Wuhan, China, se inauguró una nueva época -un acontecimiento- en la historia contemporánea. Por supuesto, con ello no emerge una nueva realidad como tal; más bien, lo que se transforma es el lugar desde el que comprendemos el mundo. De cierto modo, la proliferación global de una enfermedad es un escenario que nos resulta familiar y la experiencia acumulada al respecto es amplia (Abeysinghe, 2013; Harding, 2009).

No obstante, por la naturaleza particular de esta enfermedad, la propagación a escala mundial del nuevo brote del SARS-CoV-2 (por sus siglas en inglés) tomó por sorpresa tanto a las instancias gubernamentales como a la población en general. De manera repentina, buena parte del mundo se vio obligada a parar en seco las actividades económicas y sociales. Este padecimiento puso en evidencia tanto la fragilidad de los sistemas de salud como las desigualdades de toda índole que atraviesan a nuestras sociedades. A finales de junio de 2021, se habían contabilizado casi 194 millones de contagios y cerca de 4.2 millones de fallecimientos en todo el orbe (Johns Hopkins Coronavirus Resource Center, 2021). De acuerdo con los datos de la Secretaría de Salud de México (2021), durante el mismo periodo en el país estas cifras ascendían a casi tres millones de personas diagnosticadas con el virus y poco menos de 240 mil decesos. 
Así, el carácter global de esta pandemia puso de relieve un horizonte que generó distintas respuestas institucionales en, prácticamente, todos los órdenes. A la par de las medidas sanitarias (como desarrollo de vacunas, tratamientos y protocolos médicos adecuados), las estrategias para la mitigación de la crisis se enfocaron de manera significativa en el control social. Entre éstas se destacan el distanciamiento, el aislamiento social y la cuarentena. Sin duda, este tipo de medidas son fundamentales para aliviar el impacto de la COVID-19. No obstante, y más allá de la ralentización de los contagios, las medidas tendrán un efecto importante en la salud mental y en el bienestar de las personas, tanto en el corto como en el largo plazo (Galea, Merchant \& Lurie, 2020). Asimismo, producirán transformaciones en los modos de ser, de hacer y de estar de los sujetos (Kovacs, Caplan, Grob \& King, 2021), así como en las relaciones que estos sostienen con el entramado institucional (Nerlich \& Jaspal, 2021; Katila, Gan \& Goodwin, 2020; Banerjee \& Mayank, 2020).

Hasta ahora, la evidencia sugería que la mayor letalidad se concentraba en los sectores poblacionales más envejecidos y que padecen, además, ciertas enfermedades crónico-degenerativas (diabetes, obesidad, hipertensión, etc.). Aunque esto no quiere decir que otros rangos etarios hayan sido menos propensos a contagiarse. Con el avance de la vacunación y con la llegada de la «tercera ola» a América Latina se han mostrado efectos adversos en poblaciones cada vez más jóvenes. Lo anterior se complejiza cuando se reconoce que la propia naturaleza de la enfermedad ha contribuido a invisibilizar la situación por la que atraviesan las personas ubicadas en edades más tempranas. Más aún: sobre las/los jóvenes pesa una visión adultocéntrica que sanciona negativamente lo juvenil y que los/as estigmatiza como un vector de contagio (Day y otros, 2020; Murillo-Llorente y Perez-Bermejo, 2020).

Otros estudios (OIT, 2020; Germani, Buratta, Delvecchio \& Mazzeschi, 2020; Lago, Sanabria, Ronconi \& Zuluaga, 2021) plantean que la juventud es uno de los sectores más vulnerables ante los impactos psicosociales y económicos asociados con la COVID-19 (ansiedad, estrés, disminución de la autonomía, precarización). ${ }^{1}$ De ahí que resulte importante explorar las vivencias de este sector de la población en relación con los riesgos derivados de la pandemia, así como con los impactos socioafectivos de las medidas de control social establecidas por las autoridades gubernamentales. Ante un acontecimiento como la COVID-19 vale la pena indagar: 
¿cuáles son algunas de las coordenadas en las que se despliegan las experiencias y las biografías juveniles en un entorno pandémico? Las respuestas a este tipo de interrogantes arrojan luz sobre el impacto de la pandemia sobre los procesos de sociabilidad a partir de los que interactuamos y desde los que se produce y se reproduce el tejido social. Asimismo, permiten visualizar posibles acciones de política pública para aminorar los efectos negativos en el plano socio-afectivo.

\section{Nota metodológica}

Este trabajo tiene un énfasis hermenéutico / interpretativo. Para responder a los interrogantes planteados al principio, se obtuvieron más de sesenta testimonios ${ }^{2}$ de jóvenes de entre 15 y 29 años, hombres y mujeres, adscritos en su mayoría al sistema de educación superior y media superior en la Universidad de Guadalajara. También participaron -aunque en menor medida- jóvenes profesionistas que ya se encuentran insertos en el mercado laboral, y cuyas condiciones y prácticas son relativamente distintas a las de la población estudiantil. Las características de los sujetos que participaron en este estudio permiten inferir que cuentan con condiciones menos desfavorables para la gestión de un entorno pandémico que otras grupalidades juveniles más vulnerables y/o precarizadas, lo que delimita los alcances de este estudio.

Los testimonios fueron recabados entre marzo de 2020 y marzo de 2021. Dadas las dificultades impuestas por las medidas de mitigación de la pandemia, y frente a la imposibilidad de sostener entrevistas cara a cara, se les solicitó a los/as participantes que -a partir de la noción de espacio biográfico (Arfuch, 2007)relataran por escrito algunos de los aspectos del aislamiento y del distanciamiento social que les resultaran más significativos.

Sobre los materiales obtenidos, se efectuó un análisis de contenido. Para ello, se actualizaron las propuestas de Javier Nespereira (2014) y de Siti Mohamad (2020), en las que se plantean dos aspectos centrales: por un lado, las narrativas juveniles constituyen una parte importante del discurso público en un entorno pandémico; por otro, en el discurso público conviven de manera tensa una autoridad retórica (anclada en el espacio socio-afectivo) y una autoridad institucional (asociada con un espacio lógico-racional). De acuerdo con las 
propuestas citadas, estas fuentes de autoridad movilizan cuando menos cinco tipos de narrativas: de la incertidumbre, del agenciamiento, del enojo, de la ludicidad y de la responsabilidad. Al revisar el caso mexicano, valdría la pena incorporar dos tipos más: de la desconfianza y de la desigualdad. Esta esquematización de las narrativas permitió clasificar y analizar el contenido de los materiales recopilados mediante el programa Atlas.Ti [figura 3]. Con ello, y a partir del despliegue del espacio biográfico en un entorno contingente, se estuvo en condiciones de explorar los procesos subjetivos asociados con la emergencia de un acontecimiento [figura 1].

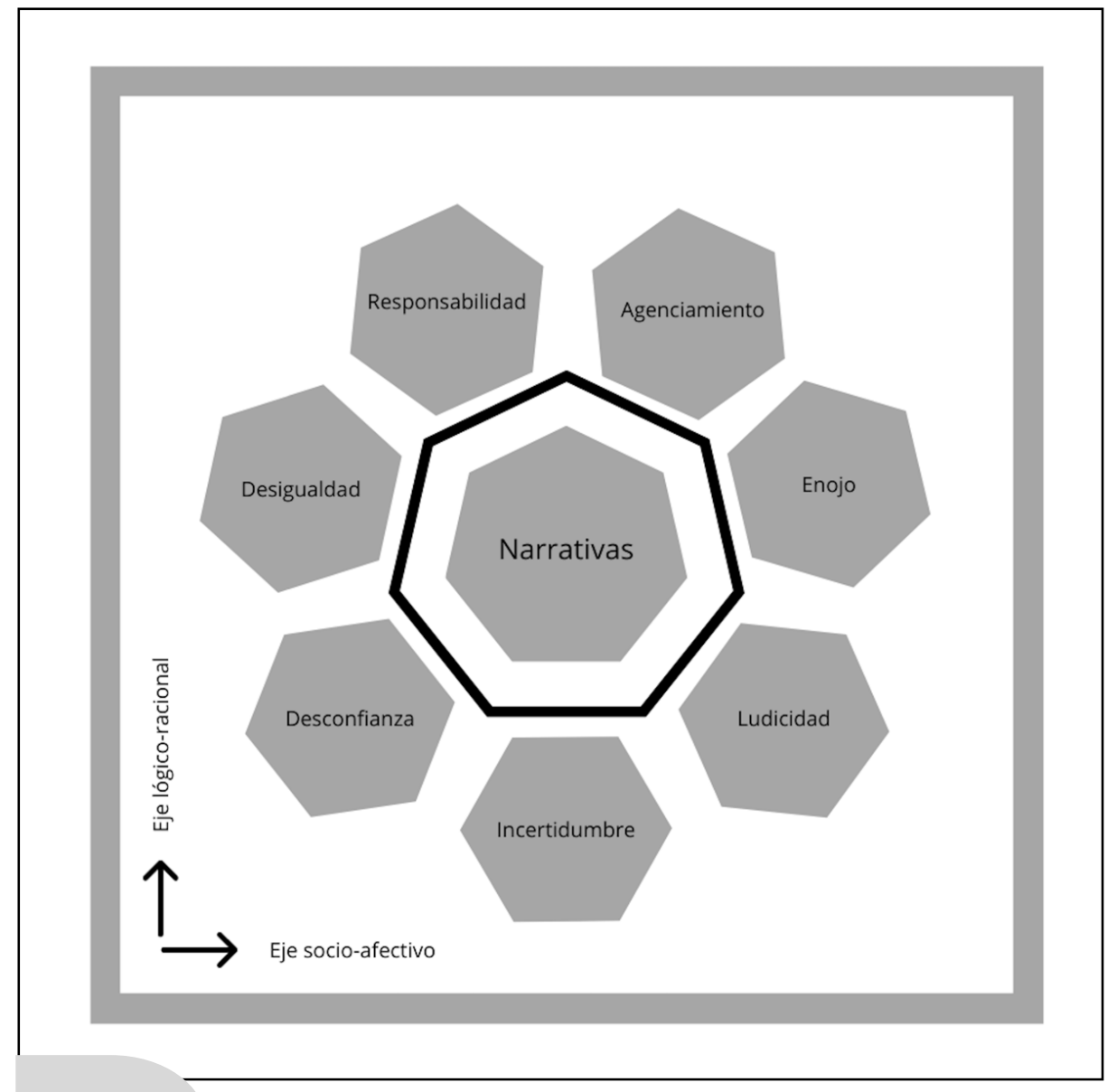

Figura 1 | Tipos de narrativas juveniles ante la COVID-19.

Fuente: elaboración propia

En cuanto a su organización, el documento está dividido en tres secciones. En la primera, se plasman algunas coordenadas conceptuales que permiten explorar las narrativas juveniles a la luz de lo que algunos/as autores/as han denominado como acontecimiento (Badiou, 2005; Žižek, 2014). En la segunda, se analiza parte de los testimonios recabados durante el trabajo de campo, tanto con el objetivo de postular un conjunto de puntos de referencia para comprender la relación del sujeto joven 
con un entorno pandémico, como de evidenciar la importancia de lo que acontece en el espacio biográfico de este sector de la población ante las medidas de control social. Por último, se ofrecen algunas conclusiones que sugieren la reconfiguración o la actualización de algunos aspectos del universo juvenil que trascienden la coyuntura pandémica actual.

\section{Acontecimiento, contingencia y espacio biográfico: entre lo individual y lo comunitario}

Habitamos la clausura y la inauguración de una época. Al mismo tiempo, transitamos por una temporalidad rizomática. Esto trae consigo la necesidad de estructurar orientaciones del pensamiento capaces de hacerse cargo de un entorno contingente. Un aparato conceptual apropiado para comprender lo que nos acontece requiere de alinearse con las perspectivas teórico-prácticas del sujeto contemporáneo. Esto es así porque, a diferencia de las doctrinas más convencionales (como sucede con aquellas que asumen un sujeto fundador, centrado y racional), en la actualidad se postula que el sujeto es una entidad escindida, contextual y, por ende, carente de una sustancia perenne. De este modo, un acontecimiento emerge, precisamente, de aquello que excede a una situación dada. Elude a la normatividad ideológica o lingüística preexistente y pone en suspenso el conjunto de reglas de escenario social concreto (es decir, lleva al límite de su vigencia a una serie de creencias más o menos consensuadas).

Con la propagación global de la COVID-19 se ha configurado lo que Badiou (2007) denomina «un punto de acontecimiento» (p. 197), es decir, una situación en la que una verdad emergente no encaja dentro del marco interpretativo predominante y, por ende, lo confronta. La fuerza de un acontecimiento radica en su capacidad de revelar verdades (es decir, narrativas) que hasta entonces permanecían latentes. Esto suele resquebrajar aquello que es socialmente aceptado. Al mismo tiempo, detona procesos subjetivos más o menos inéditos a través de una ruptura fundamental con la constante repetición de lo sabido. Sin duda, la cuarentena y el distanciamiento social constituyen ejemplos claros de lo anterior. Así, una verdad es, al mismo tiempo, tanto de naturaleza universal como de orden particular; se mueve, pues, entre lo individual y lo comunitario. En línea con Richard Rorty 
(1995), veremos que otro de los nombres posibles para esta especie de dislocación es el de contingencia. El análisis de las narrativas juveniles, que se presenta en la siguiente sección, ilustra con precisión estos aspectos.

Ahora bien, hay que reconocer que el acontecimiento no tiene una existencia autónoma o absoluta. Ocurre bajo cierta lógica, y desde una racionalidad concreta. No solo opera en el plano ontológico (como un múltiple in-fundado [Badiou, 2005]). También cuenta con una estructura implicativa, es decir, aparece en tanto que se enuncia. En otras palabras, el acontecimiento es el acontecimiento en sí, pero, también, el sujeto que retroactivamente lo nombra. De ahí la importancia de explorar las narrativas juveniles en torno a la pandemia; narrativas que se sitúan en la convergencia de la biografía personal y la historia colectiva.

De este modo, en una secuencia post-acontecimiento es posible observar la emergencia de otras subjetividades; o, mejor dicho, la emergencia de un espacio subjetivo en el que dichas subjetividades se desenvuelven. De ahí que en este artículo se postulen los ejes lógico-racional y socio-afectivo a modo de cuadrante en el que estas se despliegan. En síntesis, el campo de la subjetividad se origina a partir del proceso narrativo que revela la existencia de una situación particular y que evidencia tanto la existencia de un presente como la emergencia de un acontecimiento, lo que muestra el surgimiento de lo nuevo o, mejor dicho, de lo contingente. Tal es el caso de lo que ocurre con la COVID-19 y con las medidas gubernamentales implementadas para hacerle frente, y cómo todo ello se plasma en las narrativas juveniles.

De este modo, una mediación -inesperada pero posible- entre el acontecimiento y el análisis de las narrativas juveniles se encuentra en la noción de contingencia sugerida por Rorty (1995). Esto es así porque la característica conspicua de lo contingente radica, precisamente, en la tensión entre lo emergente y lo que permanece (una verdad instituida / una verdad que recién nace). ${ }^{3}$ En otras palabras, los vasos comunicantes entre lo público y lo privado, entre el actor y la estructura, entre la biografía y la historia están, desde ya, atravesados por la contingencia. Tanto la esfera pública como la hechura de lo biográfico son construcciones inestables que se retroalimentan, y que tienen un arreglo fundamental con respecto al contexto y al tema alrededor del que se estructura una narrativa. Las exploraciones del espacio biográfico juvenil frente a la emergencia asociada con la COVID-19 no solo permiten 
dar cuenta del proceso de producción de las experiencias individuales, sino de los núcleos socio-afectivos problemáticos de los que habremos de hacernos cargo política y colectivamente en el futuro.

En este contexto, el espacio biográfico (Arfuch, 2007) se erige como el lugar en el que convergen el actor y la estructura. Esto es así porque la idea de lo biográfico remite a un conjunto de géneros discursivos que, en términos generales, tienen como objetivo aprehender aquellos aspectos de la vida social que resultan poco tangibles (Arfuch, 2007). De ahí que en el campo de las ciencias sociales, para dotar de contenido a la categoría de actor social, se acuda, cada vez con más frecuencia, al análisis de las voces y los testimonios de los sujetos (Law, 2004; Reguillo Cruz, 2003; Ibáñez, 1994). Al explorar el espacio de lo biográfico se busca siempre la raigambre colectiva en las trayectorias individuales. Esto permite captar las texturas de la subjetividad siempre a la luz de un telón de fondo más amplio: el relato de la vida propia en contraste con la vida de todos; la bios y la zoē, tal como las refiere Giorgio Agamben (1998). Se pone de relieve, así, una ligazón recursiva entre acontecimiento, contingencia y biografía [figura 2].

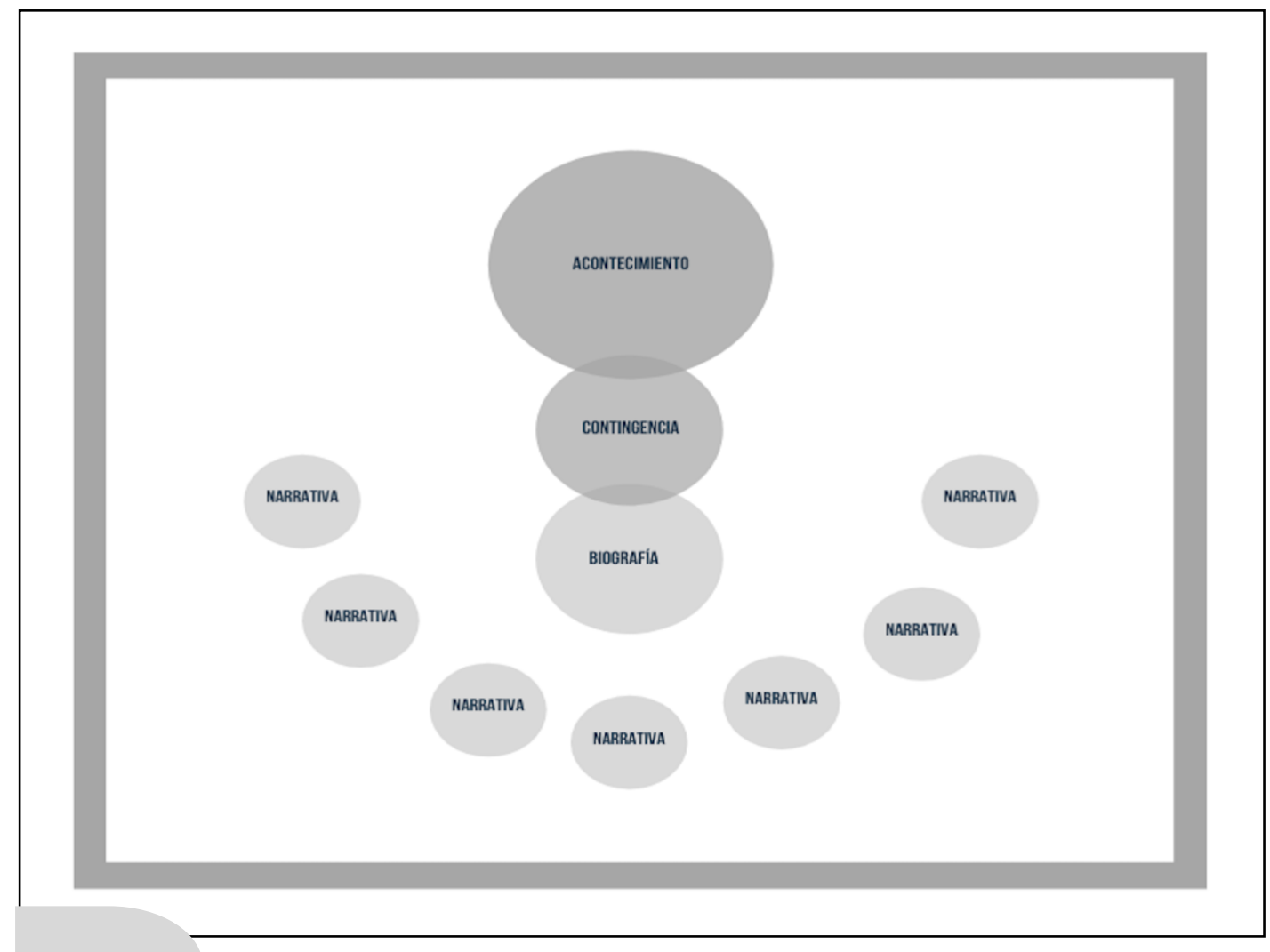

Figura 2 | Del acontecimiento a la biografía. Fuente: elaboración propia 
Para Leonor Arfuch (2007), el espacio de lo biográfico constituye un horizonte de inteligibilidad que posibilita una lectura transversal, simbólica, de las narrativas del yo en nuestro tiempo. En consecuencia, para los fines de este trabajo, el análisis de las experiencias de vida de los/as jóvenes que participaron en este estudio permite el acceso al espacio biográfico -y a los procesos subjetivos que ahí operanen relación con el advenimiento de un acontecimiento como el de la propagación global de la COVID-19.

De este modo, adquiere relevancia lo que Arfuch (2007) denomina pequeños relatos (situados en el plano de las narrativas). En otras palabras, del análisis de estos relatos mínimos emerge un proceso de expansión de las subjetividades, en cual las identidades y las historias locales se tornan más densas. Frente a este aspecto, se perfila la noción de espacio biográfico, esto es, un horizonte analítico que da cuenta de las distintas narrativas que conectan lo individual con lo colectivo. Dicho espacio permite, por ejemplo, abordar las narrativas vivenciales particulares en conjunto con la acción humana más general; así como el impacto que tiene la proliferación de dichas narrativas sobre la reconfiguración de la subjetividad.

Desde esta perspectiva, en los párrafos siguientes se analizan testimonios que dan cuenta de las maneras de vivir y de gestionar la contingencia que movilizan los/as jóvenes jaliscienses que habitan el Área Metropolitana de Guadalajara (ZMG), México, en un contexto de riesgo pandémico.

\section{Habitar la contingencia: narrativas juveniles de un entorno pandémico}

El advenimiento de la COVID-19 -como acontecimiento- alteró dramáticamente el flujo de la vida cotidiana en todos los órdenes. Para una parte importante de los/as jóvenes jaliscienses, esto constituyó una marca significativa en sus vidas, puesto que obligó a instrumentar una adecuación repentina a la contingencia en, al menos, tres áreas: el ámbito familiar y del hogar; el campo educativo; la esfera de la socialización. En torno a dichas áreas se ha producido un conjunto de narrativas que puede entenderse a partir del análisis dos ejes: uno de naturaleza socioafectiva; otro, de corte lógico-racional. Desde luego, esta distinción es meramente 
analítica, ya que en los relatos de lo biográfico narrados por los/as jóvenes los ejes mencionados se traslapan y se constituyen mutuamente.

A continuación, se presenta un esquema resumido de la heurística que guió el análisis [figura 3]. En uno de los extremos se ubican las narrativas vinculadas con el eje lógico-racional; en el otro, las correspondientes al eje socio-afectivo. En la parte inferior, en tanto, aparecen las narrativas transversales a ambos ejes.

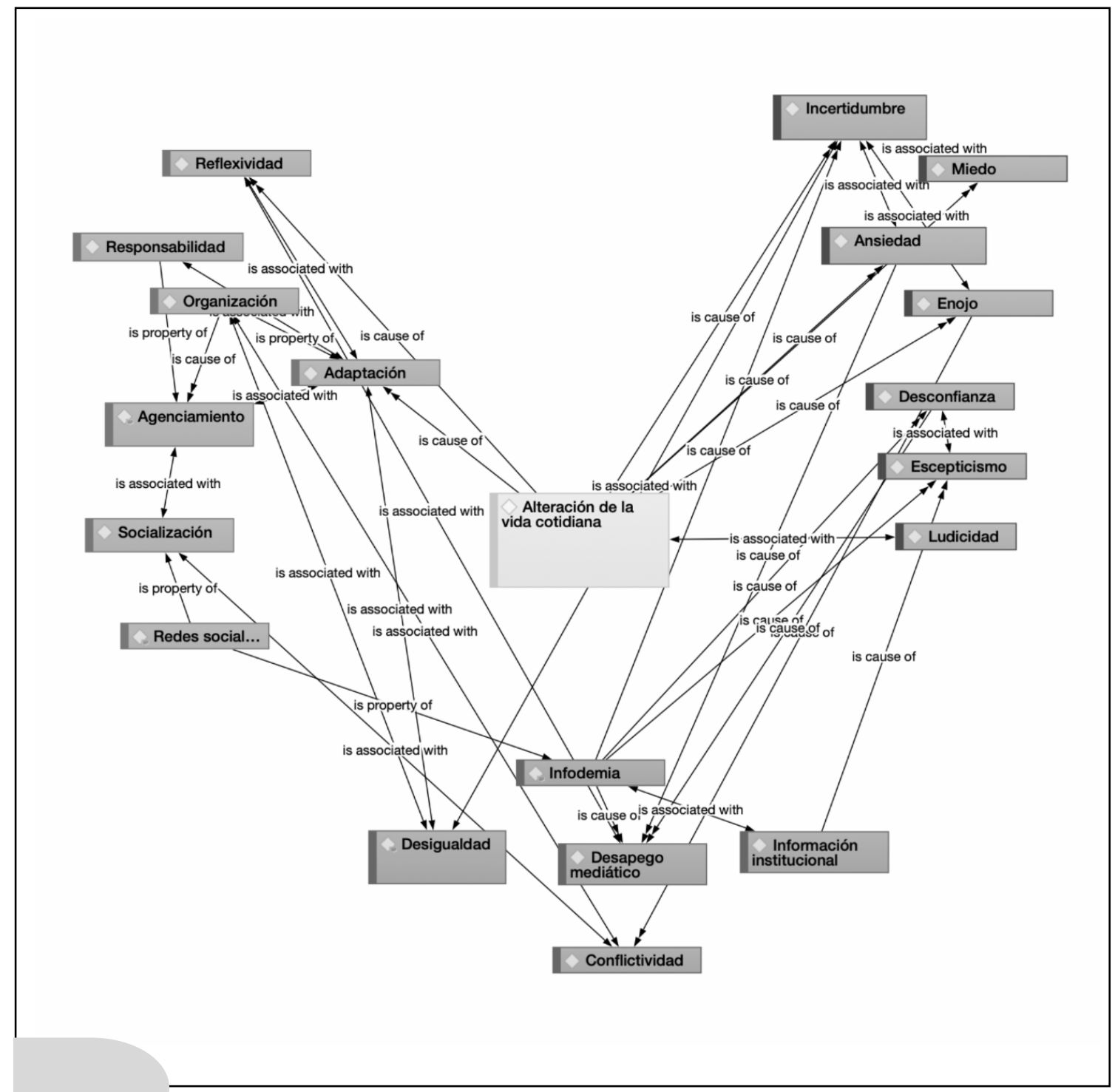

Figura 3 | Heurística de la investigación. Fuente: elaboración propia (Atlas.Ti)

De acuerdo con este esquema, la exposición de los hallazgos inicia con los relatos acerca de la emergencia sanitaria y sobre cómo esta desconfiguró las prácticas habituales, lo que trajo consigo un entorno marcado por la incertidumbre. Luego, se abordan las narrativas vinculadas al proceso de intensificación de la convivencia al 
interior de los hogares. En este punto, se destacan la visibilización de conflictividades latentes y la introspección lúdica como mecanismos para gestionar el aislamiento. A continuación, se explora el significado de algunos de los cambios ocurridos en el ámbito escolar. Finalmente, se discute acerca de la socialización tecno-digital como mecanismo para reconstruir -al menos de manera efímera- el tejido social. Sobre esto último, se destacan dos cuestiones: por un lado, a la par de la intensificación de la socialización tecno-digital se observa una tendencia al desapego mediático en relación con la información acerca de la pandemia; por otro, la capitalización política de la pandemia como un factor que reproduce y que profundiza la desconfianza del sector juvenil con respecto a las instituciones gubernamentales.

\section{Una cuarentena eterna: la incertidumbre como horizonte}

Desde el comienzo de las medidas de control social -y a un año de distancia- las narrativas de los/as jóvenes que participaron en esta investigación se condensan, en principio, alrededor de la interrupción repentina -incluso dramática- de la vida cotidiana. Esto opera en el eje socio-afectivo. El contenido de buena parte de los relatos analizados da cuenta de una suspensión de las actividades sociales y económicas que no se tenía contemplada en el horizonte cercano. Desde luego, la población contaba de antemano con un relativo conocimiento sobre la pandemia -en especial, en los primeros meses de 2020-, pero esta era procesada desde una perspectiva cercana al escepticismo; como algo lejano y ajeno, casi pasajero.

\footnotetext{
$\square$ Para ser sincera, a pesar de que el problema del Covid-19 está presente desde diciembre del año pasado, el hecho de que estuviera sucediendo al otro lado del mundo hacía que para mí no tomara tanta importancia como ahora, ya que pensaba que esto no cruzaría el Atlántico (Lily, estudiante de preparatoria, comunicación personal, 25 de abril de 2020).

La llegada de la cuarentena ha sido un proceso que aún no logro asimilar. Antes de que se proclamara oficialmente, tenía un viaje planeado para ese fin de semana que, se suponía, solo era un puente. Me fui a la playa y al principio no asimilaba que no sabía cuándo volvería a clases. Veía videos de cómo la estaban pasando en otros países, pero creía que por estar lejos nosotros no llegaríamos a tanto: me equivoqué (Valeria, estudiante de licenciatura, comunicación personal, 29 de abril de 2020).
} 
A quince meses de declarada la pandemia, el entorno incierto prevalece.

La culpa de todo la tiene el COVID. Si de rutinas hablamos, la mía la perdí, así como perdí mi casa y, por mucho tiempo, a mí misma. Vaya año, vaya bicho, vaya enseñanza que nos sigue dando... Sí, a todos y todas, me atrevo a decir, porque esta «mugrosa enfermedad», como diría mi abuela, no distinguió ni color, ni raza, ni sexo, ni espacio, ni privilegios, ni nada (Soledad, estudiante de licenciatura, comunicación personal, 22 de marzo de 2021).

Tanto en lo dicho por Lily y por Valeria, a principios de 2020, como en lo señalado por Soledad, ya durante 2021, converge una parte importante de la conversación pública que circulaba en el espacio social en torno a la emergencia sanitaria. En estos testimonios se postula, primero, un posicionamiento de incredulidad que movilizaba una narrativa vinculada con el escepticismo. ${ }^{4}$ Después, conforme se transitó hacia la «nueva normalidad», la densidad del discurso se trasladó hacia narrativas asociadas con la ansiedad y la incertidumbre. ${ }^{5}$

De este modo, se observan, cuando menos, dos aspectos relevantes: por un lado, el distanciamiento discursivo que operaba entre este sector de la población con respecto al acontecimiento COVID-19; por otro, las consecuencias de las medidas implementadas por las autoridades sanitarias ante la profundización del riesgo pandémico. En concreto: se desestabilizó casi por completo el flujo más o menos normalizado de la vida diaria, lo que en algunos casos tuvo consecuencias aciagas.

El coronavirus golpeó más fuerte de lo que esperaba. De pronto, mi familia [estaba] estresada, sin trabajo, todos en la casa, en la misma mesa.

Mi sobrino más juguetón conmigo, muchos quehaceres en la casa... En fin, de una rutina de «vida normal» pasó a ser una rutina «temporal» que se ha vuelto más infinita de lo que esperaba. No lo tengo que negar, ha sido de locos y a mi cuerpo-mente-ser le ha costado adaptarse (Juanita, estudiante de licenciatura, comunicación personal, 21 de mayo de 2020).

Una ruptura de este tipo genera vacíos que dislocan el presente y ponen en duda el futuro. La vida normal -relata Juanita- se pospone y el estado de cuarentena se eterniza. Esto no es un asunto menor: la arquitectura de la subjetividad entra en el terreno de lo eventual, de lo evanescente. Las certezas aminoran y se intensifican 
las dudas. Pero no solo se altera dramáticamente el devenir de lo cotidiano, también se generan condiciones estructurales críticas que ponen en riesgo tanto la seguridad ontológica más amplia como la subsistencia particular en sí.

En este sentido, lo dicho por los/as jóvenes es consistente con los resultados de una investigación reciente elaborada por el Centro de Estudios Estratégicos para el Desarrollo (CEED), de la Universidad de Guadalajara. En dicho estudio se señala que para $77 \%$ de los jaliscienses mayores de 18 años el aspecto económico es uno de los que ha experimentado efectos negativos debido a la pandemia. De hecho, de acuerdo con el mencionado relevamiento, $62,3 \%$ de la población que habita en Jalisco, México ha visto disminuidos sus ingresos casi a la mitad (45,5\%). Más aún: poco más del 37 \% de esta caída se debe, precisamente, a la pérdida de la fuente de ingresos (CEED, 2020). ${ }^{6}$ El contraste de estos datos con lo relatado por jóvenes como Juanita permite verificar los vasos comunicantes entre el espacio biográfico y la textura más amplia que adquiere la vida social. Queda claro que el entorno se volvió incierto debido a las medidas adoptadas para mitigar el riesgo pandémico, al grado de que hubo familias enteras que se quedaron sin fuentes de ingresos.

Al principio me sentí frustrada, porque al trasladar las clases a plataformas en línea y cerrar las escuelas todos los miembros de mi familia nos quedamos sin trabajo. Estuvimos dos semanas sufriendo un poco por esto, hasta que mi hermano propuso vender comida desde casa a domicilio. Nos organizamos, decidimos cuál era la tarea de cada integrante de la familia y ahora nos encontramos en una situación más favorable que al inicio. Aprendimos a trabajar en equipo y a sacar el mejor lado de cada persona (Alma, estudiante de licenciatura, comunicación personal, 30 de marzo de 2020).

La pandemia afectó los ingresos económicos de muchas familias ante el paro de labores por la emergencia sanitaria. Yo perdí mi trabajo. Mis padres no. Ellos siguen laborando, aunque tienen puesto en el tianguis, ${ }^{7}$ fueron clausurados temporalmente ante la pandemia. Esto los obligó a buscar otras formas de comercializar su mercancía. Pero ellos seguían saliendo de casa a pesar de la cuarentena impuesta por el gobierno. Yo, de igual forma, conseguí trabajo en la aplicación de delivery Rappi, donde realizas entregas de comidas (Eduardo, estudiante de licenciatura, comunicación personal, 24 de marzo de 2021). 
Como se observa en lo dicho por Alma y por Eduardo, con la emergencia sanitaria se trastocaron los modos convencionales con los que los sujetos solían gestionar la vida social. Ante el vacío de lo incierto, fue preciso movilizar estrategias de adaptación y de organización. En otras palabras, se estructuraron procesos subjetivos encaminados a hacerle frente a un entorno desafiante, casi hostil. Aunque lo anterior, desde luego, no ocurrió de manera tersa y aproblemática. A la par de las narrativas de adaptación y de organización (ubicadas en el eje lógico-racional) se pusieron en juego otras situadas en el plano socio-afectivo. Vale la pena destacar, desde ya, que en varios discursos es posible entrever cómo se perfila -de distintos modos y con diferentes ángulos- una narrativa de la desigualdad (en función del género; en relación con el acceso a la infraestructura o al ejercicio de ciertos derechos; frente a la distribución de las labores del hogar, etc.). A partir de la interrupción del flujo de la vida social, la desigualdad -aunque latente- se ha hecho cada vez más palpable y tiende a profundizarse conforme avanza el periodo pandémico.

La incertidumbre, pues, constituye otro de los núcleos alrededor del cual se han construido los relatos biográficos de los/as jóvenes que participaron en el estudio. Esto se ha profundizado luego de poco más de quince meses de instaurado el acontecimiento COVID-19. La alteración del devenir de lo cotidiano movilizó una narrativa que se despliega en lo socio-afectivo y que está vinculada, cuando menos, con emociones como la ansiedad, el miedo y el estrés. Estos aspectos son fundamentales para comprender la hechura del espacio biográfico en el presente, al tiempo que constituyen elementos que sin duda incidirán -en el futuro- en la esfera de lo subjetivo.

Se vive un ambiente de incertidumbre entre todos nosotros puesto que no sabemos cuándo terminará la cuarentena con seguridad. Y esto, a su vez, genera una ansiedad colectiva a causa del confinamiento y el estado económico de nuestro país. Todos los días se sienten como si estuviésemos de vacaciones o como un fin de semana en el cual tienes que realizar ciertas tareas para la escuela y después te tomas un día libre para ti. La diferencia está en que ese día libre no es diferente a los demás y aquí es donde todo comienza a tornarse un poco desquiciante y estresante (Elías, estudiante de licenciatura, comunicación personal, 23 de marzo de 2020). 
Después de quince meses de implementadas las medidas para mitigar el riesgo pandémico, la situación de incertidumbre se sostenía.

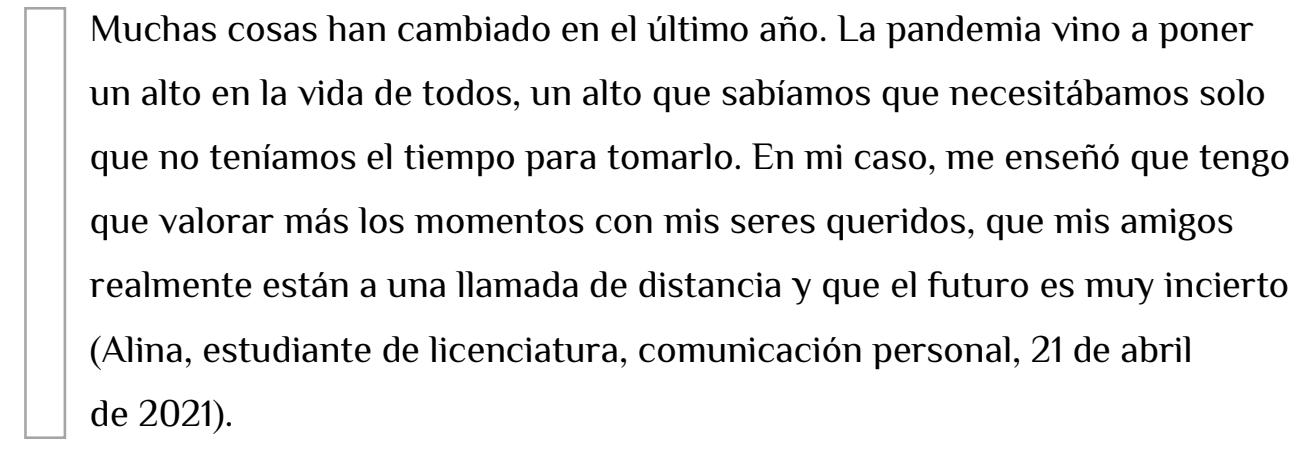

Para finalizar esta sección, es pertinente señalar la necesidad de ahondar, en investigaciones posteriores, el análisis de los efectos diferenciados que tiene la pandemia sobre la subjetividad en función de variables como el nivel socioeconómico (Gómez Granda \& Mena Rodríguez, 2021) o el género (Infante, Peláez \& Giraldo, 2021). Esto es así porque, aun cuando la población que participó en este estudio se encuentra en una situación menos desfavorable que otros sectores juveniles (son estudiantes, tienen un hogar, en algunos casos cuentan con un empleo,

etc.), resulta evidente que uno de los efectos de la pandemia fue la significativa reducción de su nivel de autonomía (y, con ello, las posibilidades de emanciparse del hogar materno o paterno).

Habría que interrogarse, pues, acerca de cómo se vive la pandemia cuando hay una serie de desigualdades acumuladas (de género, de clase, de etnia, etc.), respuestas que, desde luego, se sitúan por fuera de los límites de este trabajo. Como quiera que sea, el horizonte de incertidumbre que se vislumbra ante la juventud les ha hecho replantearse el porvenir, tanto en el eje socio-afectivo como en el lógicoracional. Sin duda, lo anterior impactará tanto en la arquitectura de la subjetividad como en la textura que adquiera el tejido social en el futuro próximo. Particularmente, en lo que refiere a las condiciones de posibilidad requeridas para transitar de la juventud a la adultez.

\section{La intensificación de la convivencia: la retirada de lo público}

La totalidad de quienes fueron entrevistados/as para este estudio comenzaron el periodo de cuarentena a mediados de marzo de 2020. Vale la pena mencionar 
que por diversas razones -que abordaremos más adelante- el cumplimiento de esta medida ha sido intermitente. A la par de la retirada de los espacios públicos, inició un proceso de adaptación y de reorganización del día a día, tanto en el plano individual como en el comunitario. Para los/as jóvenes (y para sus familias) fue necesario instrumentar una racionalidad relativamente distinta a la que era usual para hacer frente a los efectos sociales y económicos de un entorno atravesado por el riesgo pandémico. Así, en los espacios privados se generó una tensa convivencia entre lo conocido y lo emergente. Más aún, la interrupción de la vida social trajo consigo una intensificación significativa de la co-presencia al interior de las viviendas, lo que puso en marcha dos procesos importantes. En primer lugar -al menos, al principio de la pandemia-, se estructuró un ámbito propicio para la introspección y para el fortalecimiento de las relaciones intrafamiliares. ${ }^{8}$

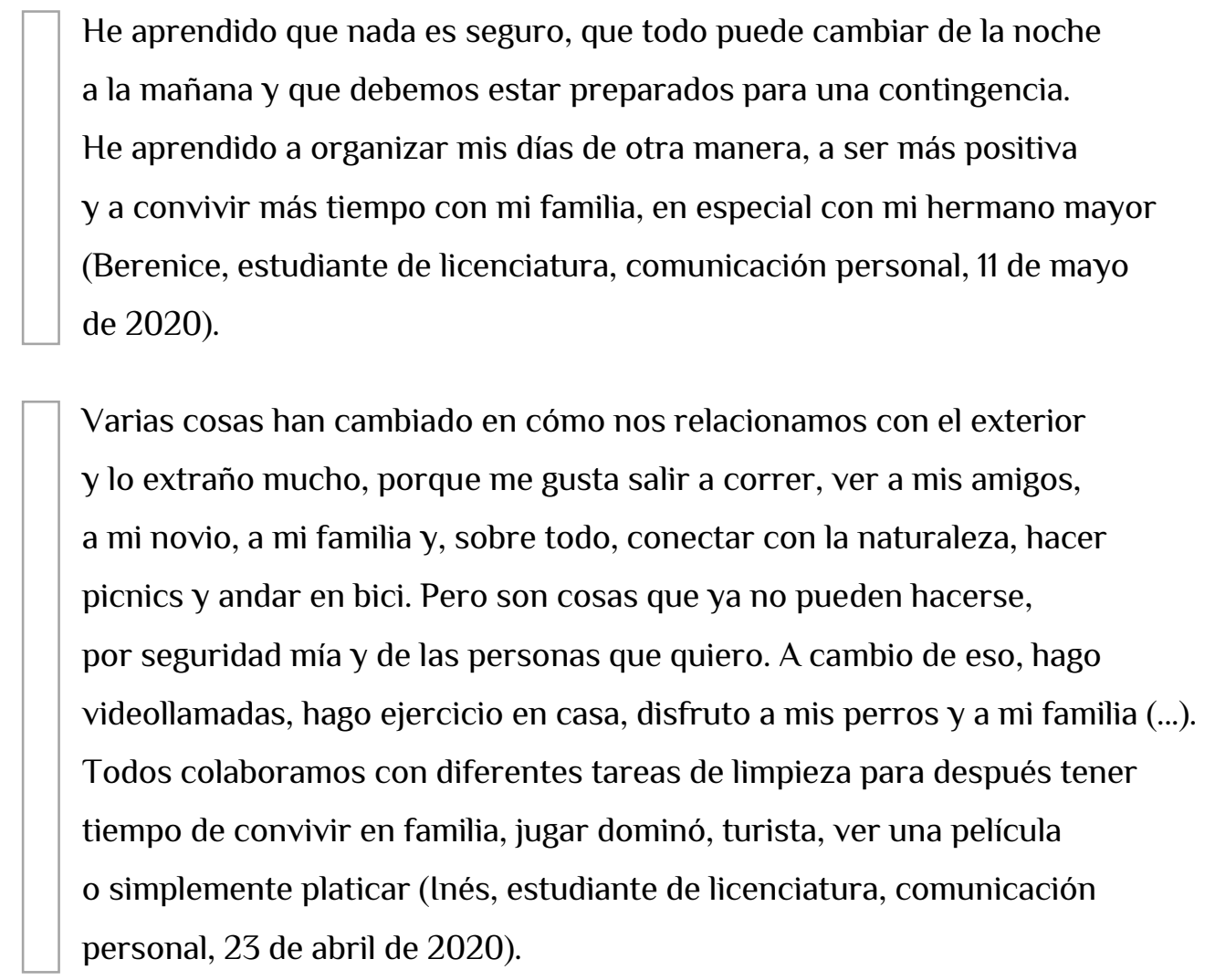

La alteración del flujo cotidiano de la vida social generó un escenario incierto. No obstante, dadas las condiciones de la población juvenil entrevistada (menos desfavorables que las de otras), el entorno pandémico representó una oportunidad para poner pausa al ajetreo diario. En este sentido, aunque la intensificación de la convivencia en los hogares se asocia con una narrativa vinculada a lo lúdico y a la reflexividad, no todas las emociones fueron positivas. 
Me costó dos semanas asimilar no la pandemia ni lo delicada que era la situación a nivel mundial sino que me iba a quedar en casa. Esto suponía nuevas lógicas de interacción entre mi familia y yo, además de conmigo mismo. No me conocía estando semanas enteras en casa. Por un momento, me sentí desanimado, abrumado e indiferente. Nada me daba sentido (Arturo, estudiante de licenciatura, comunicación personal, 12 de abril de 2020).

En segundo lugar, a raíz de la estadía obligada al interior de los hogares, se evidenció la existencia de conflictos latentes. En el caso de quienes participaron en esta investigación, dichos conflictos fueron calificados como poco significativos y se resolvieron mediante el diálogo. No obstante, no hay que perder de vista que medidas como la cuarentena aumentaron los conflictos y la violencia que padecen poblaciones que de suyo están en riesgo (como es el caso de las mujeres).

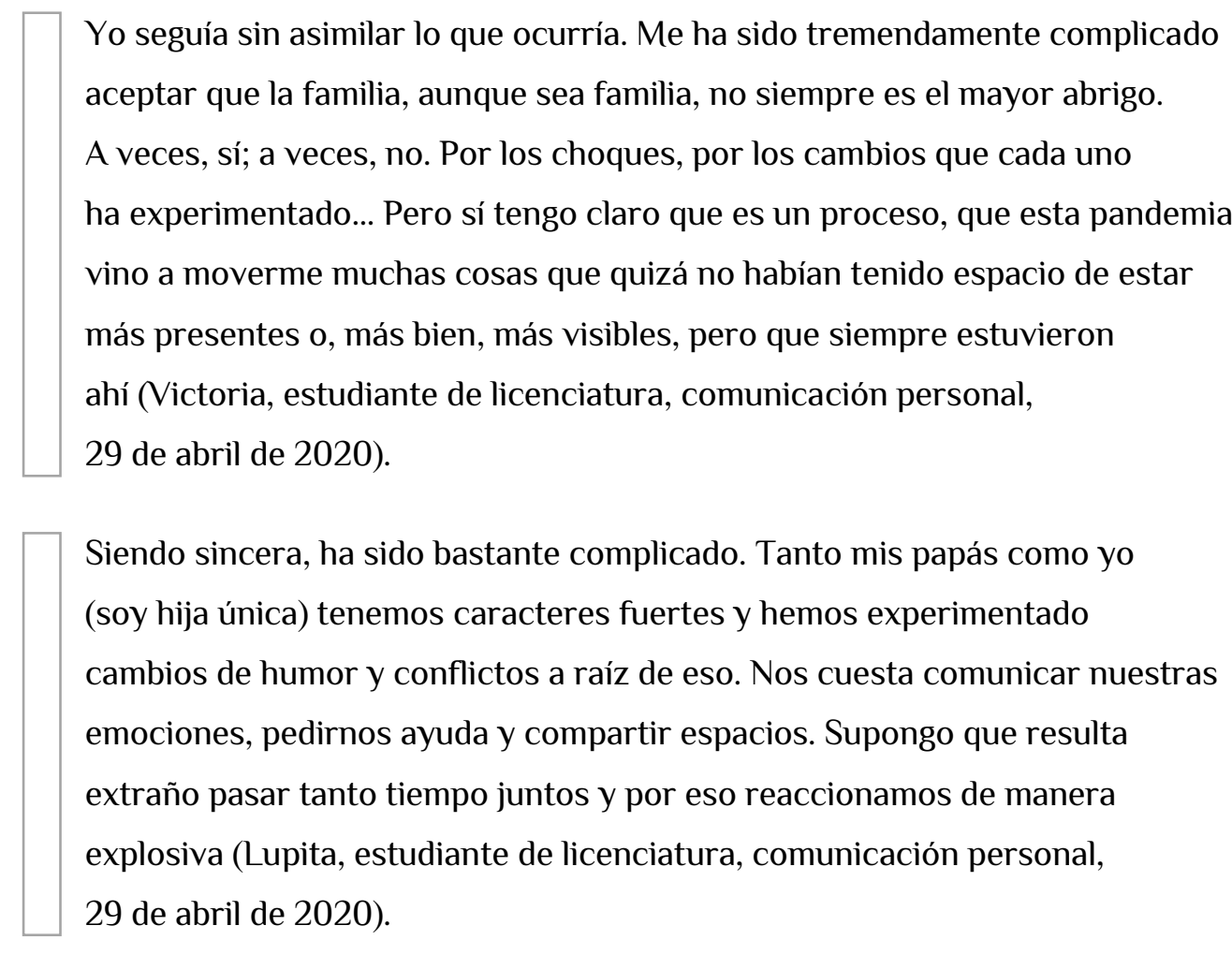

En este estudio no se encontraron casos de violencia en razón de género como tal. Sin embargo, la evidencia sugiere que este es un riesgo latente que va en aumento. ${ }^{9}$ El espacio doméstico ha experimentado una reconfiguración significativa a raíz de las medidas implementadas para contener la emergencia sanitaria. Algunos cambios han sido positivos, pero otros pueden tener consecuencias funestas y profundizar 
los riesgos y las desigualdades sociales. En este punto, habrá que interrogarse -con miras a investigaciones futuras- sobre los posibles escenarios postpandémicos que prevalecerán en los hogares. ¿Qué aprendizajes obtuvimos a partir de los modos que nos otorgamos para gestionar la incertidumbre? Las respuestas a este tipo de interrogantes son insumos cruciales para el diseño y la planificación de políticas públicas encaminadas a mitigar los efectos socio-afectivos de la pandemia.

Finalmente, hay que puntualizar que para la gran mayoría de los/as jóvenes que participaron en esta investigación el distanciamiento social y la cuarentena han sido intermitentes por diversas razones. Entre ellas, se destacan el aspecto laboral y las tareas vinculadas con el cuidado de otros (como familiares de mayor edad que requieren de atención especial y que no comparten el mismo espacio doméstico).

Las necesidades laborales y de cuidado movilizan estrategias que articulan narrativas asociadas con el agenciamiento y la responsabilidad. Tales narrativas -situadas en el eje lógico-racional- contrastan con la visión adultocéntrica que reduce lo juvenil a una condición de irresponsabilidad lúdica y de falta de empatía para con el/la otro/a. La evidencia obtenida con esta investigación sugiere, precisamente, lo opuesto. En este punto, vale la pena situar el caso de una de las jóvenes entrevistadas, que no solo estudia sino que, además, tiene tres empleos. Su testimonio -aunque no es generalizable- resulta altamente ilustrativo de los agenciamientos mediante los cuales se ponen en marcha los/as jóvenes. Aunado a lo anterior, en este testimonio se evidencian otros dos aspectos que se abordarán más adelante: la reconfiguración del espacio educativo y el incremento de la socialización tecno-digital.

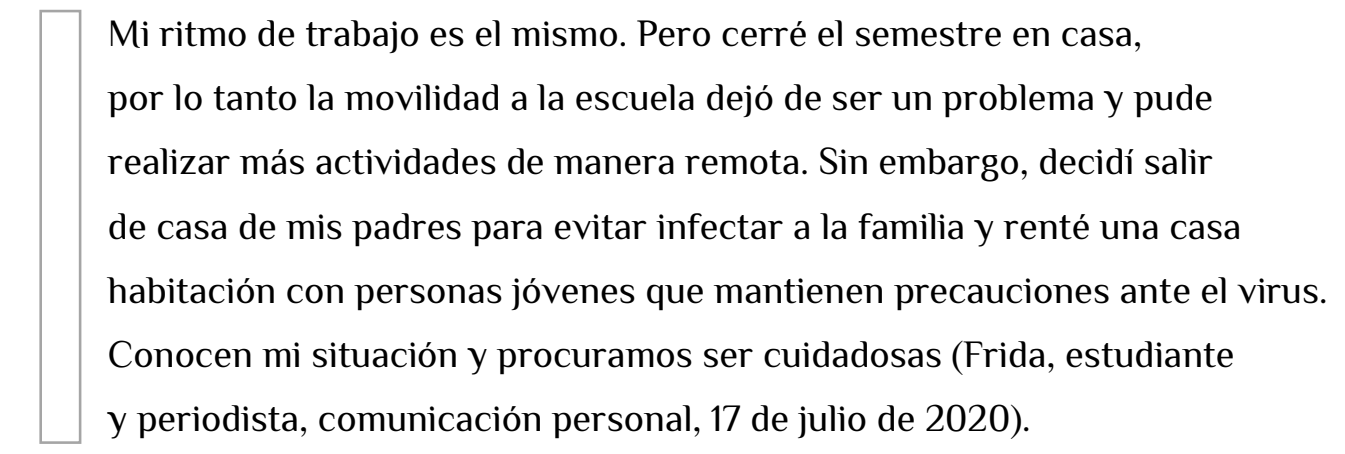

El ámbito escolar fue uno de los aspectos en los que el efecto pandémico se sintió con más fuerza, literalmente, de la noche a la mañana. De manera repentina, los/as jóvenes que participaron en este estudio se vieron obligados a adaptarse a un entorno educativo híbrido (virtual y no presencial) para el que no necesariamente 
se estaba preparado (ni la juventud ni las instituciones educativas). Desde las carencias de infraestructura hasta el trastocamiento de los tiempos áulicos, la irrupción de la COVID-19 ha constituido un desafío para el campo educativo en prácticamente todos los niveles. ${ }^{10}$

\footnotetext{
$\square$ En general, siento que más que nada el hecho de volver a casa con mis padres y adoptar esta modalidad de «ciberescuela» me ha llevado a generar un sentimiento de insuficiencia académica y de comodidad. Es difícil crear un cambio de dinámica dentro de una institución tan central y arraigada como lo es la familia y es ahí en donde siento que radica el problema. A esto le podemos añadir un sentimiento de incomodidad a causa del poco espacio personal que puedes llegar a tener debido a que ahora la casa está más llena y a todas horas puedes encontrarte con alguna figura de autoridad que te pueda ejercer, directa o indirectamente, cualquier tipo de presión (Elías, estudiante de licenciatura, comunicación personal, 23 de abril de 2020).

Cómo olvidar que estamos en plena pandemia si las clases que tomamos (yo en su momento, ahora soy privilegiada) son a través del internet de Telmex, con el de los camotes pasando," al profe que le tronó el transformador, las mamás prendiendo la licuadora cada 5 minutos y los perros, gatos, gallinas y vacas que se apoderan de los micrófonos cada que los encendemos. Y no hace falta mencionar la cantidad de ensayos, encuestas, proyectos y demás que hemos hecho utilizando al COVID-19 como sujeto imprescindible en la ecuación (Soledad, estudiante de licenciatura, comunicación personal, 14 de abril de 2021).
}

No solo se reconfiguraron el campo educativo y las prácticas que ahí se desarrollaban. Al trasladar el espacio áulico al ámbito del hogar se trastocaron el ritmo y la eficacia del proceso de enseñanza / aprendizaje. El panorama se volvió desconcertante. La intimidad devino espectáculo (Sibilia, 2008).

En este sentido, también se transformó la noción del tiempo. Antes de la pandemia, había horarios específicos asignados a cada actividad. La temporalidad estaba segmentada en función de los espacios habitados por el sujeto durante el devenir del día a día. En la actualidad, producto de la imbricación entre el espacio privado y el espacio público, la temporalidad fluye sin cortes precisos. Al menos, así ocurre 
para los/as jóvenes que participaron en este estudio. La trama sobre la que se solían tejer tanto las subjetividades en sí como la relación de estas con la dimensión institucional más amplia se dislocó. Esto es así, porque la esfera escolar todavía es central para amplios segmentos de la vida juvenil. La seguridad ontológica que suele brindar dicha esfera - en tanto uno de los anclajes de la subjetividadse erosionó de manera significativa. El mundo dejó de ser como se creía que era. Más aún, no solo se intensificó la co-presencia al interior de los hogares sino que, en paralelo, se incrementó el número de horas dedicado a actividades de naturaleza productiva / educativa.

Sí, pues yo solo llegaba a casa a dormir. Salía a las 6 de la mañana rumbo a la escuela y no regresaba hasta las 12, que volvía del trabajo. Por un lado, han cambiado, desde luego, las dinámicas de clase, el levantarte un poco más tarde, se han modificado los horarios. Mis hermanos también han sufrido ese cambio pues van a la primaria y secundaria, y he visto la difícil adaptación a la que también mi madre se ha tenido que ver sometida pues algunas tareas se las mandan por WhatsApp o correo, y otras actividades que ven en televisión, en «Aprende en casa».

Pienso que la afectación y adaptación dependen de cada persona; por ejemplo, puedo notar que emocionalmente a mis hermanos no les ha afectado tanto la cuarentena pues no están muy acostumbrados a salir. Mi madre siempre ha sido reacia a ver niños corriendo en la calle, al contrario de mis sobrinos. He sabido que se enferman por no poder salir, se estresan o tienen dolores de cabeza (Miguel, estudiante de licenciatura, comunicación personal, 29 de abril de 2020).

De un tiempo segmentado en función de los espacios de los que se solía entrar y salir durante el día, según un itinerario establecido, se pasó a una temporalidad continua, sin espacialidad concreta ni límites precisos. Las fronteras entre el exterior y el interior se hicieron porosas, y las marcas temporales convencionales se volvieron evanescentes. Esto puso de relieve la existencia de una narrativa del desconcierto, al tiempo que movilizó una narrativa del agenciamiento (necesaria para gestionar el nuevo entorno). Con todo ello, se visibilizó la desigualdad latente al interior de los hogares, lo que se relaciona con el traslado del espacio áulico al ámbito privado y se expresa en el acceso adecuado o insuficiente a la infraestructura necesaria. 
Aun cuando la población que participó en este estudio tiene condiciones socioeconómicas menos desfavorables que otros sectores juveniles, el conflicto alrededor de los equipos de cómputo fue constante.

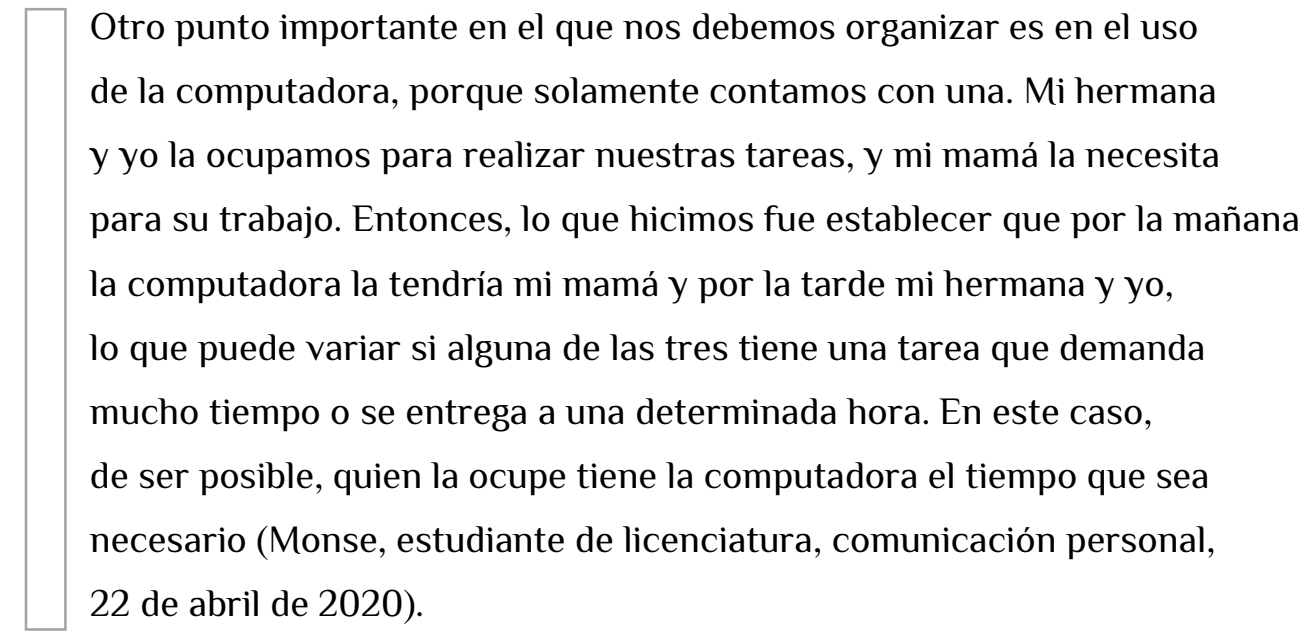

También hubo casos en los que el hogar se reconvirtió en un espacio orientado al desempeño estudiantil (de los/as jóvenes) y laboral (de los/as adultos/as).

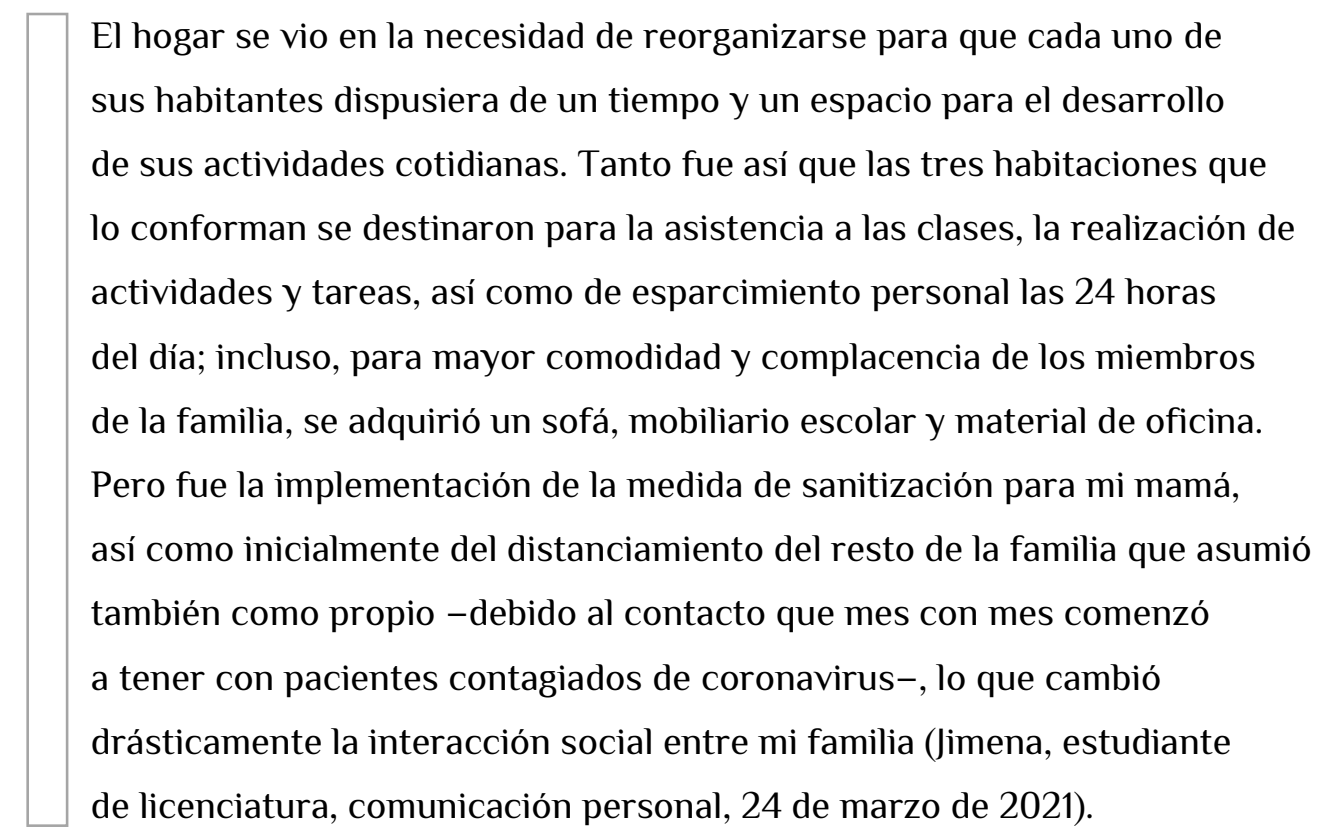

En fin, habrá que averiguar, en investigaciones posteriores, cómo opera lo anterior en contextos precarizados en donde las carencias de infraestructura son todavía más profundas. Sin duda, algunas pistas al respecto se encuentran en el trabajo de Dylan Cruz Tolosa (2020). 
Ahora bien, la reorganización de la esfera educativa no solo trajo consigo una serie de emociones asociadas con el estrés y la ansiedad ante el nuevo entorno. Como ya se dijo, mostró un conjunto de desigualdades importantes, visibles en varios niveles y expresadas con diversas intensidades. En principio, se evidenció que al interior de los hogares no se contaba siempre con recursos suficientes para hacerle frente a las condiciones educativas no presenciales. Tampoco se tenían desarrolladas las competencias y los saberes técnico-pedagógicos por parte del cuerpo docente y por algunos segmentos del alumnado. Aunado a lo anterior, la distribución del tiempo dedicado al estudio y asignado a otras labores se hizo poroso, fragmentado, y se sumó a otras desigualdades que han sido relativamente normalizadas al interior de los hogares.

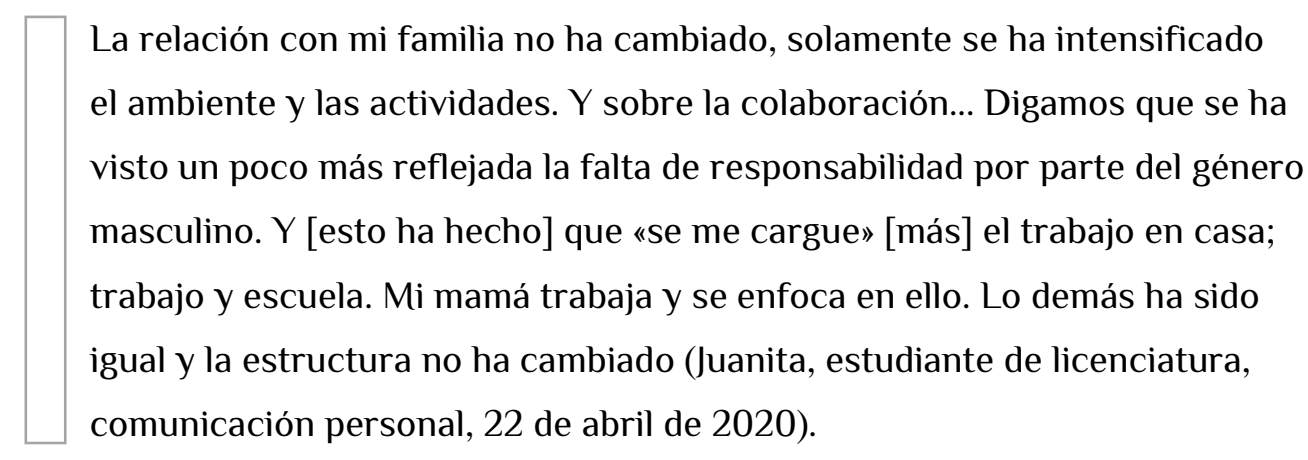

Más aún, la visibilización y la profundización de las desigualdades no se observa solo dentro de los espacios domésticos. Buena parte de quienes participaron en esta investigación mostraron preocupación acerca de cómo lo anterior ha revelado problemas latentes en el plano social más amplio. Se observa, pues, que un acontecimiento como la COVID-19 toca tanto al espacio biográfico como la dimensión estructural.

Lo que está ocurriendo en el país me causa tristeza e impotencia. Se hacen más visibles los problemas que se encuentran en la sociedad desde hace tiempo, pero que, sin embargo, no se les ha dado la atención suficiente: los trabajos no formales, la inexistencia de un sistema de salud al que todas y todos tengamos acceso, temas de urgencia ambiental, la violencia en los hogares, las personas en situación de calle, las implicaciones de depender de un sistema capitalista, la desigualdad... (Isabel, estudiante de licenciatura, comunicación personal, 16 de junio de 2020). 


\section{Socialización tecno-digital: una relación ambigua}

A la par de la esfera educativa, uno de los aspectos que más ha experimentado alteraciones durante la pandemia es la socialización (Ahmad \& Murad, 2020). El distanciamiento y la cuarentena han incidido de manera fundamental en las posibilidades de producción y de reproducción del tejido social. De acuerdo con los datos obtenidos por el CEED (2020) acerca del impacto de la COVID-19, para 56\% de los/as jaliscienses este rubro ha representado algún efecto negativo. En este sentido, el uso de las redes sociales ha experimentado un incremento crucial en tanto vía para gestionar la sociabilidad y la hechura de lo subjetivo.

Se observan, aquí, dos fenómenos importantes sobre los que valdría la pena profundizar en investigaciones futuras: la intensificación de los intercambios digitales y el «desapego mediático». Respecto del primero, ante las restricciones impuestas sobre la movilidad en el espacio público fue común el desarrollo de actividades virtuales que funcionaron como suplemento de la interacción social basada en la co-presencia (Quiroz, 2020). Es pertinente mencionar que muchas de estas actividades fueron de naturaleza lúdica, aunque lo anterior no ocurrió de manera aproblemática.

Mi cuarentena inició el 18 de marzo del 2020. Ese fue el último día que salí. Acostumbraba ver a mis amigos y a mi novio como dos veces por semana, con la medida de quedarnos en casa esto cambió mucho. Ahora solo tenemos contacto por mensaje, lo cual me frustra, porque nuestras pláticas se desenvuelven mejor cuando tenemos contacto cara a cara, sin un medio digital (Anita, estudiante de licenciatura, comunicación personal, 22 de abril de 2020).

Extraño ver a mis amigos en la prepa, claro. Pero algo que ha facilitado mucho este problema son todas las plataformas digitales para comunicarse. Hablamos diario por mensaje y jugamos en línea. Aunque no es lo mismo, es mejor que nada. A mi demás familia, como tíos y primos, los he visto pocas veces, pero nos comunicamos por teléfono. Algo que encuentro muy positivo de este «encierro» es que ha sobrado tiempo para hacer cosas que antes no podía como hacer ejercicio, leer más, aprender canciones en la guitarra y continuar aprendiendo idiomas desde la comodidad de mi casa. (Lily, estudiante de preparatoria, comunicación personal, 25 de junio de 2020). 
A principios de 2021, las narrativas eran similares.

El Internet adquirió un protagonismo en todos los ámbitos, personales y sociales, hasta convertirse en el espacio global clave para el intercambio de información y para la comunicación. Poco a poco, se cumplieron meses sin estar en contacto con nadie más que no fuera mi familia. Mis papás optaron por el envío de mensajes de texto a sus hermanos y padres, mi hermano prefirió llamarse por teléfono con sus amistades y, en mi caso, las videollamadas cobraron mayor utilidad para no perder el contacto con el resto de mis seres queridos (Jimena, estudiante de licenciatura, comunicación personal, 23 de marzo de 2021).

Junto con la intensificación de la interacción socio-digital ocurrió otro fenómeno inesperado: el «desapego mediático». En principio, vale la pena mencionar que para este sector de la población las redes sociales se erigieron como el principal mecanismo informativo acerca de las medidas sanitarias y las cifras de la COVID-19. No obstante, frente al abrumador flujo de información se implementó -desde el eje lógico-racional- una estrategia de distanciamiento con respecto a lo que ocurría. En algunos casos, se eligió filtrar la información publicada en redes, así como deslindarse de los medios institucionales. ¿Cuál es la razón de lo anterior? En buena medida esto se debe a la desconfianza que dichas instituciones suelen generar entre amplios segmentos de la población joven. ${ }^{12}$

Al inicio me mantenía muy informada con las conferencias diarias y las noticias en redes sociales. Poco a poco fui dejando de mantenerme al tanto, porque me saturó la información. De vez en cuando, tal vez una vez a la semana, veo en qué anda el mundo en materia de la pandemia. Siempre en redes sociales, principalmente Twitter, y blogs (Sandra, profesionista, comunicación personal, 18 de julio de 2020).

Uno de mis puntos negativos es la angustia, causada, principalmente, por la infoxicación que se presenta en cualquier medio de comunicación. Lo principal para contrarrestar la angustia que me provocaba esto fue filtrar mis fuentes de información, detectar cuáles me ayudaban a mantenerme informada sin llegar al extremo. A partir de esto creé un mecanismo de filtración y de legitimación de la información (Julieta, estudiante de licenciatura, comunicación personal, 22 de abril de 2020). 
Por último, se observa -al menos para el caso mexicano- que la capitalización política de la pandemia incide de manera negativa en la confianza que los/as jóvenes le otorgan al entramado institucional gubernamental.

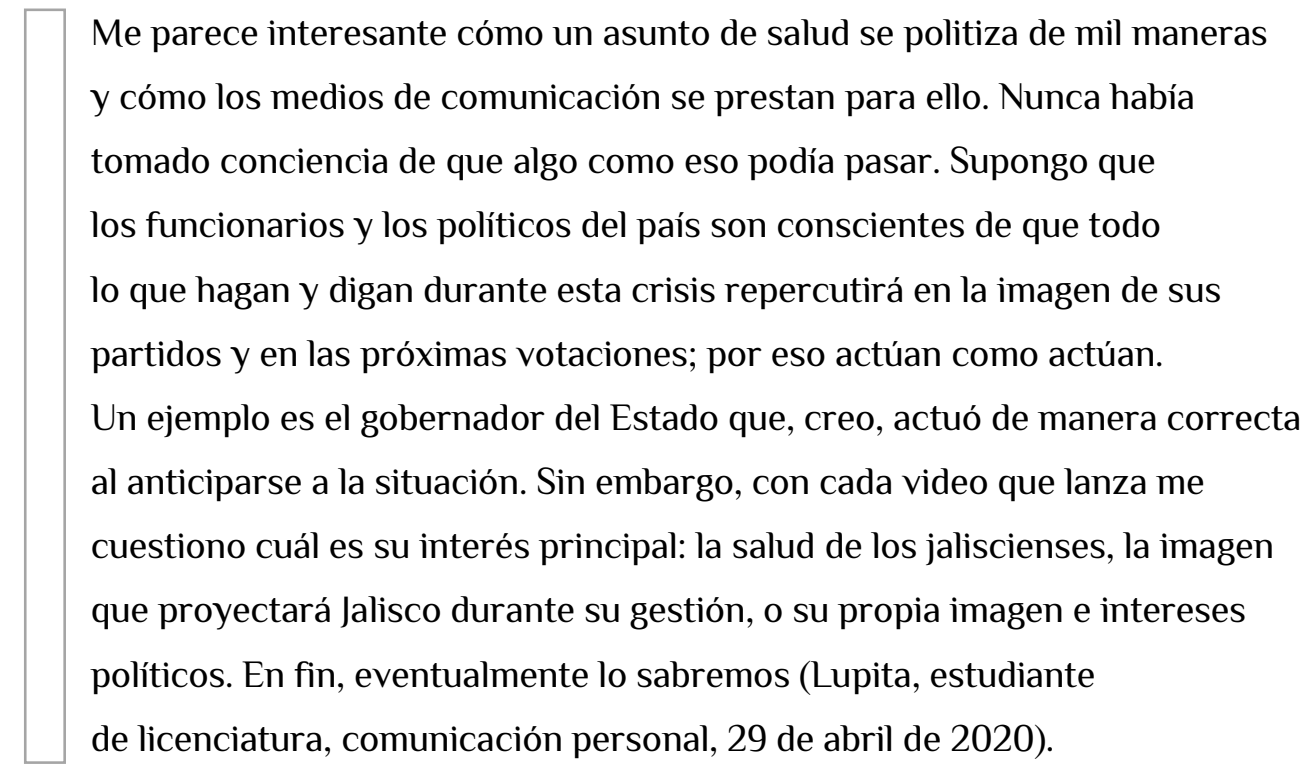

En esta sección, el énfasis se ha puesto en la interacción socio-digital, la cual desempeña, cuando menos, dos roles: se erige como un mecanismo fundamental para reconstruir tanto la subjetividad como el tejido social (de manera provisional y suplementaria a la co-presencia) y constituye el principal medio (o, al menos, uno de los principales medios) para mantenerse informado. La tendencia al desapego mediático, es decir, a la estrategia reflexiva frente a lo que una de las entrevistadas denominó «infoxicación», requiere de investigaciones posteriores. Como hipótesis puede plantease que lo anterior se relaciona con un proceso más amplio que alude a la profunda crisis de legitimidad en la que están sumergidas las instituciones gubernamentales mexicanas desde hace por lo menos dos décadas (González, 2017). La evidencia recabada aquí sugiere que dicha crisis se ha profundizado debido a la capitalización política de la pandemia en la que han incurrido algunas autoridades tanto a escala estatal como en la federación.

\section{Reflexiones finales}

Sin duda, las medidas sanitarias implementadas para mitigar los efectos del acontecimiento COVID-19 han tenido impactos significativos no solo en el ámbito 
de la salud -física y mental- (Faro y otros, 2020). También han producido, de manera repentina, transformaciones fundamentales en el plano de la vida comunitaria y social. En este documento se analizaron algunos de los impactos de lo anterior en el hogar, en la esfera educativa y en el ámbito de la socialización, a través de la exploración del espacio biográfico de los/as jóvenes jaliscienses. Así, hemos visto que para habitar la contingencia los sujetos han tenido que adaptarse a una especie de «nueva normalidad» que, en lo inmediato, movilizó narrativas vinculadas con el desconcierto, la organización y el agenciamiento juvenil.

Tales aspectos se han profundizado luego de más de quince meses desde que inició la cuarentena. Sin embargo, conforme se eterniza el riesgo pandémico, es seguro que esta experiencia tendrá repercusiones futuras, positivas y negativas, así como aprendizajes fundamentales para gestionar el riesgo pandémico a nivel personal e institucional. Estos aprendizajes deberían ser sistematizados e incorporados a los procesos de toma de decisiones públicas.

Por ejemplo, entre los fenómenos que ya comienzan a vislumbrarse en diversas partes del mundo se destacan la necesaria revalorización de la interacción social presencial (Katila, Gan \& Goodwin, 2020; Banerjee \& Mayank, 2020); la emergencia de una nueva vida cívica y la intensificación de formas de comunidad en línea entre ciertos sectores de la población que antes se encontraban alejados de esta esfera (Vlassis, 2021); el aumento de la violencia intrafamiliar, particularmente aquella que se ejerce en contra de las mujeres (Kumar, 2020; Dlamini, 2020); y el surgimiento de nuevos liderazgos políticos y de mecanismos de legitimación (Walby, 2020), entre otros. Más aún, de acuerdo con las estimaciones más recientes, se prevé que las estrategias de aislamiento y de distanciamiento social podrían continuar de manera intermitente hasta bien entrado 2022 (Kissler y otros, 2020). De ahí que trabajos como estos adquieran una relevancia crucial, en la medida en que ofrecen evidencia para comprender el despliegue de las subjetividades en un entorno contingente y para una mejor toma de decisiones en materia de políticas públicas que se hagan cargo de los impactos socio-afectivos de la pandemia. Específicamente, aquellos asociados tanto con la gestión eficaz de las consecuencias sociales de la aplicación de ciertas medidas de mitigación (como el distanciamiento social, la cuarentena obligatoria, etc.) como con la prevención de los efectos sociales negativos vinculados con dichas medidas. 
Finalmente, entre los hallazgos de esta investigación se encuentran dos aspectos relevantes que no estuvieron considerados en un principio dentro de los objetivos que se perseguían. El primero se relaciona con la visibilización de la desigualdad; sobre todo, respecto de la distribución de las labores del hogar y de cuidado y en lo que refiere a la relativa situación de privilegio en la que se encuentra el sector de la población que participó en este estudio (estudiantes de educación superior y media superior, y profesionistas insertos en el mercado laboral). Como ya se mencionó, las medidas de control de la emergencia sanitaria trajeron consigo una alteración dramática del flujo de la vida cotidiana. Lo anterior colocó a los sujetos frente al desconcierto y ante la necesidad de adaptarse a la contingencia de diversas maneras. Lo destacable es que no se percibe una correspondencia entre la reconfiguración de lo cotidiano y la reorganización de las estrategias para hacerse cargo del cuidado y del mantenimiento del hogar. Puede decirse que se intensificó la convivencia al interior del espacio doméstico, pero esto no siempre redundó en una redistribución más equitativa de las labores de producción y de reproducción social. Independientemente de la edad, en buena parte de los testimonios recabados para esta investigación se hace patente que dichas labores recaen, sobre todo, en las mujeres.

El segundo aspecto alude a la profundización de la crisis de legitimidad en la que se encuentra el entramado institucional formal. La desconfianza que produce lo anterior entre la población joven se incrementó frente al abrumador flujo de información que circuló en las redes sociales. De hecho, a la par de la intensificación de las interacciones socio-digitales, se identificó una especie de «desapego mediático», es decir, una obliteración estratégica por parte de los/as jóvenes, quienes ante el riesgo de «infoxicación» optaron por alejarse de las pantallas y del bombardeo constante de datos alarmantes. De manera particular, fue frecuente encontrar en las narrativas juveniles un rechazo a la capitalización política alrededor de la pandemia. Especialmente, en relación con las tensiones y los desacuerdos entre el gobierno estatal y el gobierno federal que, sin duda, repercutieron significativamente en la configuración de la conversación pública acerca de lo que nos acontece. 


\section{Referencias}

Abeysinghe, S. (2013). When the Spread of Disease Becomes a Global Event: The Classification of Pandemics. Social Studies of Science, 43(6), 905-926. https://doi.org/10.1177/0306312713492559

Agamben, G. (1998). Homo Sacer. Sovereign Power and Bare Life.

California, United States: Stanford University Press.

Ahmad, A. y Murad, H. (2020). The Impact of Social Media on Panic During the COVID-19 Pandemic in Iraqi Kurdistan: Online Questionnaire Study. Journal of Medical Internet Research, 22(5), e19556.

https://doi.org/10.2196/19556

Angulo, Y., Santos, M. y Siqueiros, J. (2021). Covid-19 y vulnerabilidad socioeconómica: un estudio convergente. Revista Mexicana de Sociología, (S.1.). https://doi.org/10.22201/iis.01882503p.2021.0.60067

Arfuch, L. (2007). El espacio biográfico. Dilemas de la subjetividad contemporánea. Ciudad Autónoma de Buenos Aires, Argentina: Fondo de Cultura Económica.

Badiou, A. (2005). Being and Event. London, United Kindgdom: Continuum.

Banerjee, D. and Mayank, R. (2020). Social Isolation in Covid-19: The Impact of Loneliness. International Journal of Social Psychiatry, 66(6), 527-527. https://doi.org/10.1177\%2F0020764020922269

Brooks, S., Webster. R., Smith. L., Woodland. L., Wessely,S., Greenberg, N. y Rubin, G. (2020). The Psychological Impact of Quarantine and How to Reduce It: Rapid Review of the Evidence. The Lancet, 395(10227), 839-920. https://doi.org/10.1016/S0140-6736(20)30460-8 
Centro de Estudios Estratégicos para el Desarrollo (CEED). (2020).

Estudio de seguimiento sobre la pandemia de COVID-19. Jalisco a Futuro.

Recuperado de https://cutt.ly/lURFK7h

Cruz Tolosa, D. (2020). Pandemia, jóvenes y precarización laboral.

Revista Argentina de Estudios de Juventud, (14), e051, 1-15.

https://doi.org/10.24215/18524907e051

Dlamini, J. (2020). Gender-Based Violence, Twin Pandemic to COVID-19.

Critical Sociology, 47(4-5), 583-590.

https://doi.org/10.1177\%2F0896920520975465

Day, L., Percy-Smith, B., Rizzo, S., Erskine, C., Monchuk, L. and Shah, M. (2020). To Lockdown and Back: Young People's Lived Experiences of the COVID-19 Pandemic. Ecorys. https://www.guc19.com/pdf/resourcebank/to-lockdown-and-back-research-report.pdf

Faro, A., de Andrade Bahiano, M., de Cassia Nakano, T., Reis, C., Pereira da Silva, B. y Santos Vitti, L. (2020). COVID-19 e saúde mental: a emergência do cuidado. Estudos de Psicologia (Campinas), (37), e200074. https://doi.org/10.1590/1982-0275202037e200074

Galea, S., Merchant, R. y Lurie, N. (2020). The Mental Health

Consequences of COVID-19 and Physical Distancing. JAMA Internal Medicine, 180(6), 817-818. Recuperado de

http://jamanetwork.com/article.aspx?doi=10.1001/jamainternmed. 2020.1562

Germani, A., Buratta, L., Delvecchio, E. y Mazzeschi, C. (2020). Emerging Adults and COVID-19: The Role of Individualism-Collectivism on Perceived Risks and Psychological Maladjustment. International Journal of Environmental Research and Public Health, 17(10), 3497. https://doi.org/10.3390/ijerph17103497 
González Aguirre, I. (2012). (De)construyendo la esfera pública.

Juventud y (la otra) cultura política. Revista Latinoamericana de Ciencias

Sociales, Niñez y Juventud, 10(1), 147-157. Recuperado de

https://www.redalyc.org/pdf/773/77323982007.pdf

González Aguirre, I. (2017). Y sin embargo se mueve: juventud y cultura(s) política(s) en Guadalajara. Guadalajara, México:

Universidad de Guadalajara.

González Aguirre, I. (2018). Juventud y política en México, ¿una esfera pública que evanesce? Internaciones, 5(13), 237-261.

https://doi.org/10.32870/in.v5i13.7073

Gómez Granda, P. y Mena Rodríguez, V. (2021). Espacios urbanos, jóvenes habitantes de calle y covid-19. Revista Argentina de Estudios de Juventud, (15), e053, 1-30. https://doi.org/10.24215/18524907e053

Guzmán, J. y Sosa Chávez, N. (2020). De incertidumbres y pocas certezas. Consideraciones de estudiantes jujeños en escenarios de pandemia.

Revista Argentina de Estudios de Juventud, (14), e048, 1-29.

https://doi.org/10.24215/18524907e048

Harding, P. (2009). Pandemics, Plagues and Panic. British Journalism Review, 20(3), 27-33. https://doi.org/10.1177/0956474809348261

Ibáñez, J. (1994). El regreso del sujeto. La investigación social de segundo orden. Madrid, España: Siglo XXI.

Instituto de Información Estadística y Geográfica de Jalisco (IEEG). (2020). Monitoreo de las afectaciones económicas a las unidades económicas de Jalisco por el COVID-19. Recuperado de https://cutt.ly/aURSjCd 
Infante, C., Peláez, l. y Giraldo, L. (2021). Covid-19 y género:

efectos diferenciales de la pandemia en universitarios. Revista

Mexicana de Sociología, (S.1), 169-196. Recuperado de

http://revistamexicanadesociologia.unam.mx/index.php/rms/article

/view/60072

Johns Hopkins University, Coronavirus Resource Center. (2021). COVID-19

Dashboard by the Center for Systems Science and Engineering (CSSE).

Recuperado de https://coronavirus.jhu.edu/map.html

Katila, J., Yumei, G. and Goodwin, M. (2020). Interaction Rituals and 'Social Distancing': New Haptic Trajectories and Touching from a Distance in the Time of COVID-19. Discourse Studies, 22(4), 418-440.

https://doi.org/10.1177\%2F1461445620928213

Kissler, S., Tedijanto, C., Goldstein, E., Grad, Y. and Lipsitch, M. (2020).

Projecting the Transmission Dynamics of SARS-Cov-2 through the

Postpandemic Period. Science, 368(6493), 860-868.

https://doi.org/10.1126/science.abb5793

Kovacs, B., Caplan, N., Grob, S. y King, M. (2021). Social Networks

and Loneliness During the COVID-19 Pandemic. Socius. Sociological Research for a Dynamic World, (7), 1-16.

https://doi.org/10.1177\%2F2378023120985254

Kumar, A. (2020). COVID-19 and Domestic Violence: A Possible Public Health Crisis. Journal Of Health Management, 22(2), 192-196.

https://doi.org/10.1177\%2F0972063420932765

Lago, L., Sanabria, J., Ronconi, P. y Zuluaga, P. (2021). Jóvenes y pandemia. Experiencias estudiantiles en Chubut. Revista Argentina de Estudios de Juventud, (15), e054. https://doi.org/10.24215/18524907e054

Law, J. (2004). After Method. Mess in Social Science Research. Londres, United Kingdom: Routledge. 
Liang, L., Hui, R., Ruilin, C., Yueyang, H., Zeying, Q., Chuanen, L. y Songli, M. (2020). The Effect of COVID-19 on Youth Mental Health. Psychiatric Quarterly, 91(3), 841-852. https://doi.org/10.1007/s11126-020-09744-3

Martin, M., Kap, M. y Génova, E. (2020). Entre el distanciamiento y la conectividad. Experiencias en tiempos de COVID-19. Revista Argentina de Estudios de Juventud, (14), e042, 1-12.

https://doi.org/10.24215/18524907e042

Mohamad, S. (2020). Creative Production of «COVID-19 Social Distancing» Narratives on Social Media. Tijdschrift Voor Economische En Sociale Geografie, 111(3), 347-359. https://doi.org/10.1111/tesg.12430

Murillo-Llorente, M. T. y Perez-Bermejo, M. (2020). COVID-19: Social Irresponsibility of Teenagers towards the Second Wave in Spain. Journal of Epidemiology, 30(10), 483-483. https://doi.org/10.2188/jea.je20200360

Nerlich, B. y Jaspal, R. (2021). Social Representations of 'Social Distancing' in Response to COVID-19 in the UK Media. Current Sociology, 69(4), 566-583. https://doi.org/10.1177\%2F0011392121990030

Nespereira, J. (2014). Los discursos de la pandemia. Nuevas estrategias de comunicación del riesgo en un nuevo contexto sociocultural. Cultura, Lenguaje y Representación. Revista de Estudios Culturales de la Universitat Jaume I, (XIII), 185-199. Recuperado de https://www.erevistes.uji.es/index.php/clr/article/view/1553

Organización Internacional del Trabajo (OIT). (2020). Los jóvenes y la COVID-19. Efectos en los empleos, la educación, los derechos y el bienestar mental. Ginebra, Suiza: Organización Internacional del Trabajo.

ONU Mujeres. (2020). COVID-19 y su impacto en la violencia contra las mujeres y niñas. Recuperado de https://cutt.ly/cURT9FK 
Quiroz, N. (2020). TikTok. La aplicación favorita durante el aislamiento.

Revista Argentina de Estudios de Juventud, (14), e044, 1-9.

https://doi.org/10.24215/18524907e044

Reguillo Cruz, R. (2003). De la pasión metodológica o de la (paradójica) posibilidad de la investigación. En R. Mejía Arauz y S. Sandoval (Coords.), Tras las vetas de la investigación cualitativa. Perspectivas y acercamientos desde la práctica (pp. 17-38). Guadalajara, México: Instituto Tecnológico y de Estudios Superiores de Occidente (ITESO).

Rorty, R. (1995). Contingency, Irony and Solidarity. Cambridge, United Kingdom: Cambridge University Press.

Seçer, í. y Ulaş, S. (2020). An Investigation of the Effect of COVID-19 on OCD in Youth in the Context of Emotional Reactivity, Experiential Avoidance, Depression and Anxiety. International Journal of Mental Health and Addiction, (19), 2306-2319. https://doi.org/10.1007/s11469020-00322-z

Secretaría de Salud de México (2021). COVID-19 Tablero México. Recuperado de https://datos.covid-19.conacyt.mx

Sibilia, P. (2008). La intimidad como espectáculo. Ciudad Autónoma de Buenos Aires, Argentina: Fondo de Cultura Económica.

Vlassis, A. (2021). Global Online Platforms, COVID-19 and Culture: The Global Pandemic, an Accelerator towards Which Direction? Media, Culture \& Society, 43(5), 957-969.

https://doi.org/10.1177\%2F0163443721994537

Walby, S. (2020). The COVID Pandemic and Social Theory: Social Democracy and Public Health in the Crisis. European Journal of Social Theory, 24(1), 22-43. https://doi.org/10.1177\%2F1368431020970127 


\section{Žižek, S. (2014). Event. A Philosophical Journey through a Concept. Brooklyn, United States: Melville House.}

\section{Notas}

1 La evidencia al respecto es cada vez más abundante (Brooks y otros, 2020). Por ejemplo, en Italia se han observado altos niveles de estrés y de ansiedad entre la población joven (Germani y otros, 2020). En China, se ha comprobado que el sector juvenil es uno de los más propensos a los riesgos psicosociales y de salud mental. Al respecto, Leilei Liang y otros (2020) plantean, a manera de sugerencia, que los gobiernos deberían desarrollar mecanismos efectivos para poner en marcha intervenciones sociales enfocadas en los/as jóvenes. En Turquía, en tanto, opera un proceso que İsmail Seçer y Sümeyye Ulaş (2020) denominaron desapego experiencial; es decir, un proceso mediante el que la vinculación emocional con la enfermedad se reduce al mínimo. Para el caso mexicano, son fundamentales los trabajos de Yvón Angulo, María Santos y Jesús Siqueiros (2021), y de Claudia Infante, Ingris Peláez y Liliana Giraldo (2021). En la Argentina, se destacan tanto el trabajo de Luciana Lago, Julia Sanabria, Piero Julián Ronconi y Paula Zuluaga (2021) como el de Cruz Tolosa (2020).

2 El detalle y la caracterización de los/as jóvenes entrevistados/as durante el proceso de investigación se ofrecen en el Conjunto de datos que acompaña el presente artículo.

3 Un ejemplo claro de lo anterior radica en el modo en que nos posicionamos en la actualidad con respecto al contacto físico. Antes del acontecimiento (COVID-19), era visto como una expresión socio-afectiva cálida, amorosa. Luego del acontecimiento, el contacto físico es postulado como un vector de contagio que pone en riesgo la propia vida.

$4 \mathrm{El}$ análisis del discurso público/gubernamental en torno a la pandemia queda por fuera de los límites de este trabajo. No obstante, sí puede decirse que la narrativa del escepticismo ha sido instrumentada incluso por Andrés Manuel López Obrador, representante del poder ejecutivo en México. Sus declaraciones y sus posturas ante la pandemia causaron fuertes polémicas.

5 En este punto, resultaría ilustrativo contrastar los argumentos de este estudio con los hallazgos del trabajo realizado por Juan Guzmán y Nicolás Sosa Chávez (2020), en el que se explora el caso de los/as jóvenes de Jujuy, Argentina.

6 En este sentido, otros estudios confirman lo anterior. Por ejemplo, en el monitoreo realizado por el Instituto de Información Estadística y Geográfica de Jalisco (IIEG, 2020) se observa que 76,6\% de las unidades económicas encuestadas reportó una reducción de sus ventas mayor al 50\%. Ante un escenario de este tipo, en 35\% de estas unidades se ha considerado un cierre definitivo. Por otra parte, valdría la pena contrastar estos datos con la reflexión proporcionada por Cruz Tolosa (2020), en la cual se explora el caso de los/as jóvenes que habitan en la Ciudad Autónoma de Buenos Aires, Argentina. 
7 La palabra "tianguis» proviene del náhuatl «tianquiztli» y alude a una especie de mercado público, popular e itinerante, en el que se comercia prácticamente cualquier género de mercancías y de servicios.

8 Vale la pena puntualizar que esta tendencia aplica para los sectores juveniles con condiciones socioeconómicas relativamente más favorables. Lo que aconteció con la población joven más vulnerable y precarizada ofrece un panorama radicalmente distinto, más desolador. Véase por ejemplo el trabajo de Angulo, Santos y Siqueiros (2021).

9 El caso de las mujeres y las niñas es particularmente grave en un país como México. De acuerdo con organismos como ONU Mujeres (2020), se estima que la violencia de género se ha agravado debido a la COVID-19. Entre las repercusiones sociales asociadas con esta enfermedad, el mencionado organismo destaca: mayores niveles de estrés y de inseguridad económica y alimentaria; aumento de las agresiones de toda índole encaminadas a intimidarlas o a denigrarlas en el ámbito doméstico; mayor riesgo de explotación sexual de las mujeres jóvenes que habitan un contexto de precarización.

10 Vale la pena mencionar aquí los argumentos de Victoria Martín, Miriam Kap y Elena Génova (2020), quienes reflexionan de manera certera sobre el impacto de la pandemia en la esfera educativa.

11 En algunas regiones de México, es frecuente que por las mañanas o por las noches transiten por los barrios populares diversos tipos de vendedores ambulantes. Uno de los más típicos es el personaje que ofrece camotes endulzados (batatas). Es característico que dicho personaje anuncie sus productos mediante un silbato sumamente estridente. A este personaje se lo conoce como «el de los camotes".

12 Desde luego, este no es un fenómeno nuevo ni exclusivamente vinculado con el entorno pandémico. La crisis de legitimidad en la que están sumergidas las instituciones gubernamentales en México se remonta a varias décadas atrás (González Aguirre, 2012, 2017 y 2018). 